www.jmscr.igmpublication.org

Impact Factor 5.244

Index Copernicus Value: 83.27

ISSN (e)-2347-176x ISSN (p) 2455-0450

crossref DOI:_http://dx.doi.org/10.18535/jmscr/v4i8.42

Journal Of Medical Science And Clinical Research

IGM Publication

An official Publication of IGM Publication

\title{
Root Resorption with Orthodontic Intrusion Review
}

(Research Article)

Authors

T.M.Sree Vidhya ${ }^{1}$, Dr Navaneethan ${ }^{2}$

${ }^{1}$ BDS (Final year), Saveetha Dental College

${ }^{2}$ MDS (Orthodontics), Saveetha Dental College

Email: vidhyadevan94@gmail.com

\begin{abstract}
AIM AND OBJECTIVE: This article reviews root resorption with micro implant assisted intrusion

BACKGROUND: Orthodontic intrusion is a common treatment approach in managing orthodontic esthetic and functional problems, including gummy smile and deep bite. Amongst, different type of orthodontic procedures, intrusion is found to be undoubtedly a difficult procedure. Micro implants are found to produce offer an effective skeletal anchorage which is an assist to orthodontist since it renders the intrusion of both anteriors and posterior teeth an increasingly streamlined procedure from mechanical support. Apical root resorption is abnormal consequences in orthodontic treatment. Root resorption produce shortening and breakdown the integrity of teeth from the arch. This article reviews the systemic evaluation of root resorption with micro implants assisted intrusion

REASON: The purpose of the systemic review is evaluate the various factor of root resorption with micro implant assisted with intrusion.
\end{abstract}

\section{INTRODUCTION}

Root resorption is a pathological process that causes a shortening of the dental root. Although this condition is generally asymptomatic and missed in diagnosis, it may result in tooth mobility and even tooth loss if not diagnosed and treated early. ${ }^{(1)}$ In orthodontics, induced inflammatory root resorption is a form of pathologic root resorption related to the removal of hyalinized areas of the periodontal ligament following the application of orthodontic forces and is considered an undesirable but unavoidable iatrogenic consequence of orthodontic treatment (2).
The root resorption may compromise the continued existence and functional capacity of the affected tooth, depending on their magnitude since the root structure is changed, However, as the process of root resorption during orthodontic treatment is usually smooth and ends when the force is removed ${ }^{(3)}$.

Dental intrusion often constitutes an integral part of orthodontic treatment in order to imp rove sagittal and vertical incisor relationships, to correct interincisal angle and consequently, the gingival line and restore the esthetics of smiling. ${ }^{[3]}$ For many years, dental intrusion was considered impossible or problematic and was associated 
with numerous side-effects from the periodontium and cementum (root resorption).

The aim of this review is to enhance the aetiology, risk factors, and development factors of root resorption in orthodontic intrusion with micro implants in form of overview.

\section{ETIOLOGY OF ROOT RESORPTION}

Determining the eitological factors of root resorption requires a thorough detailed history of the patient, previous accidents, trauma, previous orthodontic treatment. Various authors has quoted that resorption of root is based on theatre td biological varialbilty, genetic constituents, mechanical factors. The mechanism behind the root resorption is found to be a complex factor ${ }^{(4)}$.

Abuabara et al 2007, quoted that Orthodontic tooth movement is based on force-induced periodontal ligament and alveolar bone remodeling ${ }^{(5)}$. So, orthodontic forces represent a physical agent capable of inducing inflammatory reaction in the periodontium ${ }^{(6)}$. When a tooth moves, a necrosis of periodontal ligament on the pressure side with formation of a cell-free hyaline zone occurs. This event is followed by osteoclast resorption of the neighbouring alveolar bone and bone apposition by osteoblasts on the tension side (5) the resorption process of dental hard tissues seems to be triggered by the activity of some cytokines as well as that of bone. Immune cells migrate out of the capillaries in the periodontal ligament and interact with locally residing cells by elaborating a large array of signal molecules ${ }^{(7)}$. According Consolaro et al. ${ }^{(8)}$ the causes of root resorption should be related to the loss of root surface cementoblasts.

\section{TYPES OF ROOT RESORPTION}

Root resorption is known to occur after trauma and in response to inflammation ${ }^{(9)}$. Ankylosis may well be related to reparative processes in replacement resorption ${ }^{(10)}$. Orthodontists are principally interested in External Apical Root Resorption (EARR), which is a form of surface resorption. EARR refers to the loss of apical root material only, other forms of resorption can be observed ie. Lateral (cervical) resorption on the buccal surface of molar roots during rapid maxillary expansion treatment ${ }^{(11)}$.

Micro CT studies have identified microscopic areas of EARR of $0.1 \mathrm{~mm}$ in depth in $90 \%$ of nonorthodontically treated permanent teeth. Small resorption lacunae particularly on the lateral aspects of roots are thought to be harmless and a normal finding reflecting the on-going balance between resorption and deposition. The incidence of EARR shows a wide range of reporting, with histological studies showing a higher incidence than clinical studies. Females are more susceptible than males ${ }^{(12)}$. The most readily affected sites are (in order) maxillary laterals, maxillary centrals, mandibular incisors, the distal root of mandibular first molars, mandibular second premolars and maxillary second premolars ${ }^{(3)}$.The risks of resorption do seem to increase after the age of 11 years ${ }^{(12)}$

\section{METHODS TO DETECT}

Most commonly resorption is detected towards the end of treatment on a root paralleling or end of treatment orthopantomogram. Long cone parallel technique periapicals have the highest chance of reflecting the severity of the case. Carefully performed, they allow some quantification of the problem. They are not traditionally taken as part of an orthodontic pretreatment work-up. Animal and histological studies show the problem has been traditionally under-reported, whilst clinical studies have a tendency to minimise it. ${ }^{(13)}$

\section{ORTHODONTIC INTRUSION WITH MINI IMPLANTS}

Orthodontic intrusion is to be aimed to corrective procedure for anterior and posterior open bite or correcting the extruded teeth due to the missing of opposing teeth .It can be done using anchorage from the adjacent teeth ${ }^{(14)}$. The development of mini implants in recent decades has enabled efficient anchorage no requirement of tooth support, no aesthethic compromise (15). Many 
studies have that orthodontic intrusion using mini implants placement .Before treatment procedure periapical radiographs and cephalogram were taken and treatment plan was made for corrective procedure. Most of the studies have shown root resorption in apical two third in relation to upper central incisors and upper maxillary molar in case class 2 anterior open bite. ${ }^{(16)}$

A study of 500 adults of age 20 yrs treated consequently from Four orthodontics practices. Mutai once applaince with $0.022 * 0.028$ inch bracket were used in all cases. The radiograph of cone beam paralleling techinque were used.On radiographic examination, total root length was measured from the Incisal edge to the root apex. Root width was measured from mesial to distal outline of the root from $4 \mathrm{~mm}$ from the apex.the measurement were made using transparent ruler. cephalometric analysis were made and diagnosed, in each appoinment the periapical radiograph were taken to analysis the tooth movement of root resorption $^{(17)}$.

Mean apical root resorption of the most se- verily resorbed central and lateral incisor and canine per patient was $1.47 \mathrm{~mm}$ (SD 1.40), $1.63 \mathrm{~mm}$ (SD 1.24 ), and $1.25 \mathrm{~mm}$ (SD 1.52), respectively. The second run of regression analyses revealed that tooth length was associated with root resorp- tion for all teeth, that history of earlier orthodontic treatment was a preventive factor for central and lateral incisors, and that endodontic treatment was a preventive factor for lateral incisors and canines. Horizontal movement of the apex was associated with root resorption for central incisors, apical root width was negatively associated for lateral incisors, and time of anterior elastics and Class II elastics wearing was associated with root resorption for canines. In addition, atypical root shape was a risk factor for root resorption of central incisors. ${ }^{(17)}$

In another study quoted by Fazin, shahin, sample chosen was 10 ten female reported to hospital with average age of $43.75 y$ rs with over erupted maxillary molars contributions fort prosthodontics placemat and no of them had undergone orthodontic treatment before and they have no active periodontal disease in the beginning of treatment. ${ }^{(18)}$

They used Absoanchor mini implants for intrusion of molars intrusion which has long and short divers for minister insertion. Stainless teeth backers were fbanded to extruded teeth in oder to deliver a force $.017 x .25$ in tungsten molybdenum alloy and attached to mini stew headend and lifgated to the bracket. the parallel cone beam tehnique were used to measure the amount of intrusion and or resorption in three intervals. To measure the root resorption the line passing the furcation point of the toothed was drawn to the reference axis and perpendicular distance of root apex to this line was computed in pixel units in three time intervals .Molars were successfully intruded clinically and radiographic evaluation indicated palatal root resorption of molars. Mean value of root resorption during active treatment was $0.1 \mathrm{~mm}$ and during retention period $0.3 \mathrm{~mm}$.In mesio buccal root average was $0.4 \mathrm{~mm}$. There were no root resorption furcation areas with no correlation with patient age. ${ }^{(19,20,21)}$.

Several other studies with mini implants assisted intrusion shows root resorption of 0.20 to $0.4 \mathrm{~mm}$ in average.

\section{CONCLUSION}

To conclude many clinical studies have shown that orthodontic intrusion with mini implants shows root resorption but aeitopathogenesis behind the fact were not enhanced. Only orthodontic tooth movement will not be only reason patient's genetic predisposition, biological varialbilty, mechanical and physical changes may also be the reason behind the root resorption.

\section{REFERANCE ORTHO}

1. Ahangari, Z.; Nasser, M.; Mahdia, M.; Fedorowicz, Z.; Marchesan, M.A. (201). Interventions for the management of external root resorption. Cochrane Database Syst Rev, Jun 16, 6, CD008000 
2. Brezniak, N.; Wasserstein, A. (1993). Root resorption after orthodontic treatment: Part 1Literature review. Am J Orthod Dentofacial Orthop, 103, 1, 62-6.

3. Brezniak, N.; Wasserstein, A. (1993). Root resorption after orthodontic treatment: Part 2 Literature review. Am J Orthod Dentofacial Orthop, 103, 2, 138

4. Bartley, N.; Türk, T.; Colak, C.; ElekdağTürk, S.; Jones, A.; Petocz, P.; Darendeliler, M.A. (2011). Physical properties of root cementum: Part 17. Root resorption after the application of $2.5^{\circ}$ and $15^{\circ}$ of buccal root torque for 4 weeks: a microcomputed tomography study. Am J Orthod Dentofacial Orthop, 139, 4, e35360.

5. Abuabara, A. (2007). Biomechanical aspects of external root resorption in orthodontic therapy. Med Oral Patol Oral Cir Bucal, 12, 8, E610-3.

6. Giannopoulou, C.; Dudic, A.; Montet, X.; Kiliaridis, S.; Mombelli, A. (2008). Periodontal parameters and cervical root resorption during orthodontic tooth movement. J Clin Periodontol, 35, 6,501-6

7. Jäger, A.; Zhang, D.; Kawarizadeh, A.; Tolba, R.; Braumann, B.; Lossdörfer, S.; Götz, W. (2005). Soluble cytokine receptor treatment in experimental orthodontic tooth movement in the rat. Eur J Orthod, 27, 1, 1-11.

8. Consolra, A.; Franscischone, T.R.G.; Furquim, L.Z. (2011). As reabsorções as múltiplas ou severas não estão relacionadas a fatores sistêmicos, suscetibilidade individual, tendência familiar e predisposição individual. Dent Press J Orthod, 16, 1, 17-21.

9. Tronstad, L. (1988). Root resorption-etiology, terminology and clinical manifestations. Endodontics \& Dental Traumatology. 4, 241-52.

10. Andreasen, J.O. (1985). External root resorption: its implication in dental traumatology, paedodontics, periodontics, orthodontics and endodontics. International Endodontic Journal. 18, 109-18.

11. Harris, E.F., Kineret, S.E.\&Tolley, E.A. (1997). A heritable component for external apical root resorption in patients treated orthodontically. American Journal of Orthodontics \&Dentofacial Orthopedics. 111, 301-9. Heithersay, G.S. (1999). Invasive cervical resorption: an analysis of potential predisposing factors. Quintessence International. 30, 83-95.

12. Linge, B.O.\&Linge, L. (1983). Apical root resorption in upper anterior teeth. European Journal of Orthodontics. 5, 173-83.

13. Darendeliler, M.A., Kharbanda, O.P., Chan, E.K., Srivicharnkul, P., Rex, T., Swain, M.V., Jones, A.S.\&Petocz, P. (2004). Root resorption and its association with alterations in physical properties, mineral contents and resorption craters in human premolars following application of light and heavy controlled orthodontic forces. Orthodontics \& Craniofacial Research. 7, 79-97.

14. BAE, S. M.; PARK, H. S.; KYUNG, H. M.; KWON, O. W.; SUNG, J. H. Clinical application of micro-implant anchorage. J. Clin. Orthod., Boulder, v. 36, no. 5, p. 298-302, May 2002.

15. ARAUJO, T. M. Ancoragem esquelética com miniimplantes. In: LIMA FILHO, R. M. A.; BOLOGNESE, A. M. Ortodontia: arte e ciência. Maringá: Dental Press, 2007.

16. ARAUJO, T. M.; NASCIMENTO, M. H. A.; BEZERRA, F.; SOBRAL, M. C. Ancoragem esquelética em Ortodontia com miniimplantes. Rev. Dental press Ortodon. Ortop. Facial, Maringá, v. 11, n. 4, p. 126-156, jul./ago. 2006

17. Eric J. W. Liou a and Peter M. H. Chang .Apical root resorption in orthodontic patients with en-masse maxillary anterior retraction and intrusion with miniscrews 
18. Farzin Heravi, a Shahin Bayani, b Azam Sadat Madani, c Mehrdad Radvar, d and Najmeh Anbiaee Intrusion of supraerupted molars using miniscrews: Clinical success and root resorption

19. Umemori M, Sugawara J, Mitani H, Nagaka, Kawamura H. Skeletal anchorage system for openbite correction. Am J Orthod Dent Orthop 1999; 115:166-74? 10.

20. Erverdi N, Keles A, Nanda R. The use of skeletal anchorage in open bite treatment: a cephalometric evaluation. Angle Orthod 2004; 74:381-90. 11.

21. Ari-Demirkaya A, Masry MA, Erverdi N. Apical root resorption of maxillary first molars after intrusion with zygomatic skeletal anchorage. Angle Orthod 2005; 75:761-7. 